\title{
CONCERNING THE CLINICAL CLASSIFICATION OF INTRACRANIAL TUMORS *
}

\author{
PERCIVAL BAILEY, Ph.D., M.D. \\ Associate in Surgery, Peter Bent Brigham Hospital; Arthur Tracy Cabot \\ Fellow, in Charge of the Laboratory of Surgical Research, \\ Harvard Medical School \\ BOSTON.
}

In the course of an address (unpublished) before the American College of Surgeons, ${ }^{1}$ on "Brain Tumor Statistics," it was pointed out by Dr. Harvey Cushing that there was great difficulty in comparing statistics from different clinics because of the great variation in classification. It is believed that a record of the method employed in a clinic where large numbers of such cases are handled will be of value. The routine series entering the Peter Bent Brigham Hospital between April 1, 1919, and Dec. 1, 1919, has been chosen, all these cases having been under my personal supervision.

There were admitted between the dates given, 118 patients supposed to be suffering from some sort of intracranial new growth involving the brain. Some of the difficulties involved in classification may be appreciated from the following history which will be, in common with all the succeeding ones, condensed to positive findings, omitting the results of all other routine examinations unless they have a bearing on the case.

CASE 1 (P.B.B.H. Surg. No. 10598).-Endothelioma of the right occipital lobe. Preliminary subtemporal decompression. Subsequent extirpation in a two-siage operation. Recovery.

June 7, 1919, M. W., aged 61, a tailor, recommended by Dr. Nightingale of Worcester, Mass., entered the hospital complaining of failing vision and weakness of the right leg.

Chronology of Symptoms.-For six months he had suffered with occasional frontal headaches, not severe or continuous, and progressive failure of vision; for three months dull aching pain in the right arm and leg at times. Lately there had been weakness of the right leg.

Positive Findings.-There were tortuosity of the retinal vessels with patches . of exudate along their course, no measured elevation; slight asymmetry of surface temperature, the left arm being warmer than the right; slight motor weakness in the left leg.

Discharge Diagnosis.-Brain tumor and arteriosclerosis were suspected.

He was admitted for the second time on June 23, 1919.

\footnotetext{
* From the clinic of Dr. Harvey Cushing, Peter Bent Brigham Hospital Boston.

1. New York City, Oct. 21, 1919.
} 
Course.-Since he had been discharged the headaches and pains in the right leg and arm had entirely disappeared.

Positive Findings.-Inconstant left ankle clonus, marked dilatation of extracranial blood vessels and bilateral low-grade choked disk were present.

Clinical Diagnosis.-Possible endothelioma.

Operation.-June 27,1919 , a right subtemporal decompression was performed. The brain was tense and vascular.

Postoperative Notes.-Ankle clonus disappeared. The decompression area was tense. He was discharged July 9, 1919.

Discharge Diagnosis.-The diagnosis was tumor cerebri, unverified; possible endothelioma. ${ }^{2}$

The patient was admitted for the third time on Sept. 3, 1919.

Course.-He had continued free from headaches. Vision was slightly improved. For six weeks there had been a feeling of numbness and tingling in the left arm and gradual development of weakness.

Positive Findings.-The decompression area was tense and bulging. The extracranial veins were enormously dilated. There was bilateral low-grade choked disk with secondary optic atrophy. The left pupil was slightly larger than the right. There were left homonymous hemianopsia; slight emotional left facial weakness; hypesthesia over the entire left half of the body below the trigeminal area, more evident toward the distal portions of the extremities. Sense of position was impaired in the left arm and leg. The tendon reflexes were exaggerated in the left arm and leg, with ankle clonus.

Clinical Diagnosis.-The diagnosis was cerebral tumor of the right postcentral region.

Operation.-Sept. 5, 1919, an osteoplastic exposure of the posterior right hemisphere was made. Palpation of the dura disclosed a hard area in the posterior extremity of the field, suggesting underlying endothelioma. Closure was made without opening the dura because of vicious bleeding from the bone.

Second Stage Operation.-Sept. 12, 1919. The bone-flap was again reflected. An occipital lobe endothelioma was extirpated from the attached surface of the falx. Blood transfusion was performed.

Postoperative Notes.-Recovery was rapid and uneventful in spite of the fact that the patient insisted on fasting during the Jewish holidays. He was discharged Sept. 30, 1919.

Discharge Diagnosis.-The diagnosis was cerebral tumor, verified; endothelioma.

Comment.-Although at the time of his first discharge, because of the indefinite nature of his complaints and in view of his age, it was felt that arteriosclerotic changes would account for his troubles, the possibility of tumor was not overlooked, and he was told to report occasionally for observation. It will be noted that at the time of his second admission the only motor sign was on the left side, while all his symptoms had been on the right. A right subtemporal decompression was done to relieve his eyesight while more definite localizing

2. Dr. Cushing based this impression solely on the dilated vessels of the scalp. The roentgen-ray findings were negative. He felt so sure that he sent for the patient to return although the old man was well satisfied with the results of his decompression. 
signs developed. His third admission resulted from a letter to his physician inquiring about his progress. A glance at the following classification will show that this patient on his various admissions was successively in each of the three main groups in which tumor cases have come to be tabulated in this clinic.

\section{Classification of Authors' Cases}

The 118 cases were divided thus:

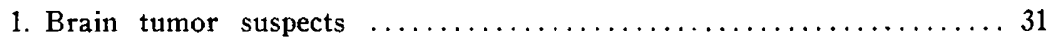

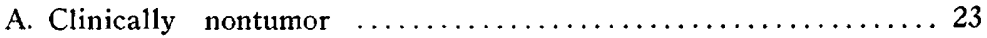
Cases admitted as brain tumor which after thorough study were not so regarded.

B. Clinically doubtful $\ldots \ldots \ldots \ldots \ldots \ldots \ldots \ldots \ldots \ldots \ldots \ldots \ldots$ Cases admitted as brain tumor in which the findings were doubtful but operation was performed and no evidence of tumor found.

C. Clinically tumor $\ldots \ldots \ldots \ldots \ldots \ldots \ldots \ldots \ldots \ldots \ldots \ldots \ldots \ldots$ Clinically localizable tumor, but operation although exposing location disclosed no evidence of tumor.

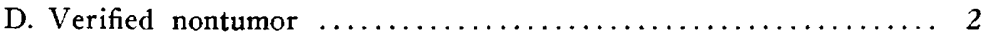
Clinically localizable tumor, but pathologic lesion determined and absence of tumor verified at necropsy.

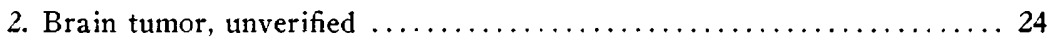

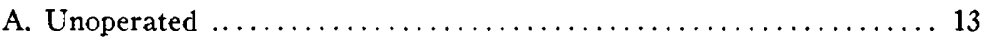

B. Unlocalized $\ldots \ldots \ldots \ldots \ldots \ldots \ldots \ldots \ldots \ldots \ldots \ldots \ldots \ldots \ldots$

Decompressed to relieve pressure symptoms.

C. Undisclosed $\ldots \ldots \ldots \ldots \ldots \ldots \ldots \ldots \ldots \ldots \ldots \ldots \ldots \ldots \ldots \ldots, 6$

Explored but no lesion found.

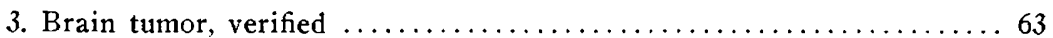

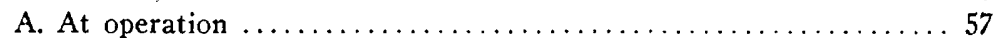

B. At necropsy, unoperated $\ldots \ldots \ldots \ldots \ldots \ldots \ldots \ldots \ldots \ldots \ldots \ldots$

C. At operation and necropsy $\ldots \ldots \ldots \ldots \ldots \ldots \ldots \ldots \ldots \ldots \ldots \ldots$

D. At necropsy, unverified at operation $\ldots \ldots \ldots \ldots \ldots \ldots \ldots$

The diagnosis written on the history sheet at the time of discharge of the patient usually includes only the main group plus the presumptive or established pathologic diagnosis, but all the necessary information for placing a case in the foregoing scheme may be gathered from the front sheet of the history after discharge. For example, if the diagnosis reads "brain tumor suspect; encephalitis" and there is no record of operation or necropsy examination, the patient obviously belongs in $1 \mathrm{~A}$; if the necropsy findings are recorded, the case falls in $1 \mathrm{D}$.

The patient whose history was given at the outset, on his first admission would have been placed in Group 1A as tumor suspect, clinically arteriosclerosis. On his second admission, owing to his choked disk and the tension found at operation, his case fell into $2 \mathrm{~B}$ or tumor unverified, though operated, because unlocalizable and therefore 
decompressed. At the last admission he was shifted to Group $3 \mathrm{~A}$ when the tumor was verified at operation.

Many times the final classification was determined by developments during the patient's stay in the hospital. The clinical picture was often very doubtful but gave sufficient grounds for undertaking an exploratory operation. If, during the course of the operation, no evidence of tumor was disclosed, the patient was classified under $1 \mathrm{~B}$; if evidence was disclosed, (excessive tension, etc.) under $2 \mathrm{C}$; if the tumor was found and verified, under $3 \mathrm{~A}$. The necessity for change sometimes occurred after a patient had left the hospital, as happened with L. McN., Surg. No. 11187, reported elsewhere, ${ }^{3}$ who was discharged as "brain tumor unverified, presumably basilar glioma" and later came to autopsy. Examination of the brain made it necessary to shift her from $2 \mathrm{C}$ to $1 \mathrm{D}$. There was found a meningo-encephalitis.

I. BRAIN TUMOR SUSPECTS: THIRTY-ONE CASES, 26.27 .

PER CENT.

A great many patients were admitted to the clinic with a diagnosis of brain tumor who proved to have some other disease. They have all been placed in this main group, which will be examined in some detail as at once the most difficult and most interesting. A straightforward case of acoustic neuroma or pituitary adenoma, easily recognized and routinely removed, causes little excitement, but a borderline case in which one must employ all his wits and every instrument of precision at his command arouses the most intense interest.

A. Clinically Nontumor.-In this group are placed patients admitted with a diagnosis of presumptive brain tumor in whom, on examination, conditions other than tumor were found, which it was felt would explain the symptoms. No operation was therefore undertaken. They were usually referred by general practitioners, although occasionally by neurologists.

The clinic has of course, little control over the number of cases that fall into this group. When a physician writes that he has a case of brain tumor which he wishes to refer there is little possibility of determining that no tumor is present before the arrival of the patient. And often these patients have puzzling and interesting conditions. The following case of unusual interest is a good example.

CASE 2 (P.B.B.H. Surg. No. 10229).-Intracranial arteriovenous aneurysm with tumor syndrome of the cerebello-pontile angle. Dislocation of atlas.

3. Bailey, P.: Contribution to the Histopathology of "Pseudotumor Cerebri," Arch. Neurol. \& Psychiat. 4:401, 1920. 
April 2, 1919, Francis T. N., aged 48, a miner, was admitted to the hospital, referred by Dr. A. F. Fischer of Hancock, Mich., with complaint of pain in the back of the neck, dizziness, double vision and facial paralysis.

Chronology of Symptoms.-August, 1914, a singing noise in the left ear began which continued for two years, then ceased, leaving partial deafness. November, 1916, dizziness developed. April, 1917, diplopia appeared. December, 1917, paralysis of the left half of the tongue and a sensation of numbness and thickness appeared. February, 1918, there was weakness of the left side of the face. October, 1918, there was complete paralysis of the left side of face. June, 1918, severe pain in the neck followed a misstep. January, 1919, the left ear drum was punctured; this was followed by repeated severe hemorrhages. February, 1919, there was severe pain in the left ear followed by discharge.

Positive Findings.-These were: left pupil larger than the right; paralysis of the left external rectus; fine nystagmus on looking to the left; hypersensitivity to pain in the area of the middle division of the left trigeminus; left peripheral facial paralysis; disturbance of taste on the posterior part of the tongue; left recurrent laryngeal paralysis; Rinne's test negative in the left ear; atrophy of the left half of the tongue; slight ataxia and adiadokokinesis in the left arm; pain on flexing the head on the chest; red mass projecting into the left external meatus; shrill and continuous humming murmur over the left carotid sheath, heard best around the left ear. In the roentgenogram there was seen to be a dislocation of the atlas.

Discharge Diagnosis.-Brain tumor was suspected clinically; there were intracranial arteriovenous aneurysm and dislocation of the atlas.

Comment.-Most cases in this group are not of sufficient interest to be detailed here. They will be reported elsewhere. It might, however, be of interest to note the final diagnosis arrived at in this clinic. There were twenty-three cases, distributed as follows: Ménière's syndrome, essential epilepsy, cerebral thrombosis (with epilepsy), encephalitis (lethargic), polyneuritis (with encephalitis), cerebral hemorrhage, congenital malformation, marasmus (with optic atrophy), hysteria (simulating pituitary tumor), otosclerosis, post-traumatic psychosis, congenital nystagmus, hysteria (simulating acoustic tumor), syphilitic meningitis, otitis media, cephalalgia (neurasthenic), senile psychosis, intracranial arteriovenous aneurysm, choroiditis, psychasthenia, cerebral embolism, toxic amblyopia and multiple sclerosis. Occasionally such a patient returned, as already noted in the case of $\mathrm{M}$. W., Surg. No. 10598, from whom an endothelioma was removed from the falx cerebri in the occipital region on his third admission.

B. Clinically Doubtful.-In all the cases in the preceding group it was reasonably certain that a tumor was not present, but occasionally a patient would present himself with sufficient evidence to lead to an exploration, although the diagnosis was questionable. Often in such cases a tumor was found. If, however, normal brain or definite pathology other than tumor was disclosed, the patient was placed among the suspects. The absence of tumor of course cannot always be finally 
established without a necropsy examination, even though other lesions are found. An example will be given later (F. S., Med. No. 11985).

Five instances of this sort were found, and each presents features of interest. ${ }^{4}$

Case 3 (P.B.B.H. Surg. No. 11271).-Epilepsy zeith mental deterioration and doubtful symptoms. Exploration. Negative findings.

Oct. 6, 1919, John W., aged 25, a farmer, recommended by Dr. E. A. Ludden of North Brookfield, Mass., was admitted to the hospital with complaint of "fainting spells."

Chronology of Symptoms.-For nine years he had had attacks of transitory loss of consciousness, often, but not always, accompanied by muscular twitchings. According to the mother, the right side was always involved more than the left and at times only the right side was involved. There were no involuntary twitchings. The attacks occurred with increasing frequency until lately practically every day brought an attack. For four months he had had hallucinations of sight. Lately he had practiced sodomy and other sexual perversions.

Positive Findings.-The temperature was markedly irregular ranging from 97 to $101 \mathrm{~F}$. The tendon reflexes in the lower extremities were sluggish. The roentgenograms showed enormous dilation of the diploeic veins with pressure absorption in the frontal region. There was marked mental retardation. The patient was seen to have a typical jacksonian attack beginning in the right arm and extending to the face, while standing, without falling but with transitory unconsciousness. The perimetric examination was questionable because of lack of cooperation.

Clinical Diagnosis.-There was a possible endothelioma of the left frontal region.

Operation.-Nov. 1, 1919, an osteoplastic exposure of the left frontal lobe was made. The extracranial vessels were much dilated, and there was excessive bleeding from the large diploeic veins. The dura was tense, and at the upper anterior corner was a thickened and roughened area. Underneath no tumor was found, although the brain was congested and tense. An attempt to enter the ventricles was unsuccessful.

Postoperative Notes.-Recovery was uneventful, and the patient was discharged Dec. 18, 1919, unimproved.

Discharge Diagnosis.-Brain tumor was suspected; epilepsy of doubtful etiology.

Comment.-The history in this case was not reliable. Neither the patient nor his mother could give a connected story. Objective signs of destruction of motor cells were lacking, but the attack seen was quite definitely jacksonian. Pressure signs were absent, but the dilated extracranial vessels and enormous diploeic veins were suggestive. During the operation, the dilated veins, the bleeding diploe, the absorption of bone, the discolored dura, everything down to the actual moment of opening the dura seemed to increase the certainty of the diagnosis.

4. The publication of this article was delayed by the absence of the writer from the clinic for several months. This section is left as originally written, and the progress of the patients since discharge is indicated in the footnotes. 
The nature of the lesion is uncertain, and the gradually increasing mental deterioration, the epileptic attacks gradually becoming more frequent, the circulatory changes in the skull and the irregular temperature require some explanation. A deep lying glioma may yet be found. ${ }^{5}$

Case 4 (P.B.B.H. Surg. No. 11130).-Convulsions of cerebellar type with doubtful tumor symptoms. Exploration. Negative findings.

Sept. 9, 1919, Eloise T., aged 44, a housewife, recommended by Dr. J. W. J. Marion, of Calais, Me., was admitted to the hospital with complaint of headaches and vomiting.

Chronology of Symptoms.-For six months she had had attacks of severe suboccipital headache with vomiting, unaccompanied by nausea. The attacks were sudden in onset and short in duration. Lately they had been much more frequent. For the past week there had been slight weakness and tremor of the right hand and prickly sensations in both arms.

Positive Findings.-There were fine nystagmoid twitchings on lateral movements of the eyeballs; slight incoordination of the left hand; tendon reflexes on the left side slightly exaggerated; slight edema of the nasal borders of the optic disks.

Cinical Diagnosis.-The diagnosis was: possible cerebellar tumor.

Operation.-A bilateral suboccipital craniotomy was performed Sept. 15, 1919. There was no unusual tension, but considerable respiratory difficulty; no internal hydrocephalus. Puncture of each cerebellar hemisphere disclosed nothing abnormal.

Postoperative Notes.-During the first week there were periods when the respiratory rate reached as low as 7 per minute. The patient complained of pain in the arms at first but improved rapidly and was discharged Oct. 21, 1919, entirely free from symptoms.

Discharge Diagnosis.-Brain tumor was suspected; essential pathology undetermined.

Comment.-This patient lived in the Maine woods, far away from surgical aid, and since it was feared that a severe attack might prove fatal, in case a tumor were present, before she could be transported to a hospital, an exploratory operation was advised. If, in this case, an internal hydrocephalus had been disclosed, she would have been listed as having a case of cerebellar tumor, unverified. It may be that the

5. Note from the Monson State Hospital, Palmer, Mass., Oct. 20, 1920: "This patient died May 23, 1920, and the cause of death was given as epilepsy with status epilepticus. He was admitted to this institution Dec. 18, 1919. . . His seizures averaged from three to twelve of the G. M. type and from none to 260 of the P. M. type. . . . I regret that no autopsy was obtained . . ."

In this clinic a man was recently operated on, John P., Surg. No. 13161, who gave a history of mild sensory attacks over a period of sixteen years. Pressure symptoms and motor attacks had appeared only within the last six months. At operation an extensive cerebral glioma was found. 
obstruction was too recent and transient to result as yet in a dilatation of the ventricles. ${ }^{6}$

CASE 5 (P.B.B.H. Surg. No. 11256).-Internal hydrocephalus zevith postoperative cerebral hernia and cerebrospinal fluid leak. Successful closure.

Oct. 2, 1919, Hayman C. H., aged 22, a bank teller, referred by Dr. J. W. Alsobrook, of Plant City, Fla., was admitted to the hospital with complaint of paralysis of the left arm and leg and discharge from the right side of the head.

Chronology of Symptoms. - December, 1918, he had an acute tonsillitis, followed by right otitis media. The ear drum was punctured, followed by persistent discharge. March 15, 1919, the discharge from the ear ceased. April 7 , he had a headache. April 8 , he had a violent headache and staggering gait. April 11, the ophthalmologist diagnosed choked disk and advised operation at once. Operation was refused. April 15, operation was performed. A transverse incision through the right temporal muscle was made. The temporal lobe was explored but no abscess was found. The wound was packed with gauze. April 17, another unsuccessful attempt was made to find the abscess. The wound was again packed and the packing was changed every day. Hernia of the brain developed. April 24, there was beginning weakness in the left arm followed soon by weakness in the left leg. May 1, the fungus sloughed entirely and the brain receded into incision. May 3, the incision had healed. May 5, the patient had severe headache. May 7 , the wound was opened and kept open by drains ever since.

Positive Findings.-The findings were: a right temporal protrusion from which cerebrospinal fluid was escaping; bilateral secondary optic atrophy; fine nystagmus to right; left facial paresis; Weber's test lateralized to the right and Rinne's test negative for the right ear; deviation of the tongue to the left; paresis of the left trapezius; suboccipital tenderness on the right side; flaccid paralysis of the left arm except for some spasticity of the biceps and flaccid paresis of the left leg; exaggeration of biceps, triceps, periosteal, knee and ankle reflexes on the left side with a positive Babinski reflex and wrist and ankle clonus; hypesthesia of the left half of the body for touch, temperature and muscle sense; epigastric, abdominal and cremaster reflexes absent on the left side.

Clinical Diagnosis.-The diagnosis was possible cerebral tumor.

Operation.-Oct. 9, 1919, a right osteoplastic exploration disclosed a sinus leading down to an enormously dilated right ventricle. No other lesion was found. The defect was closed.

6. The patient was readmitted March 8, 1920, Surg. No. 12044. Vision had progressively failed to almost total blindness. Frequent attacks of vomiting developed, with generalized convulsions and incontinence. There were no headaches. Examination showed anosmia, bilateral primary optic atrophy, fibrillary twitching of the muscles around the mouth, absent knee and ankle jerks, slight ataxia of the hands and paresis of the left internal rectus muscle. March 19,1920, a transfrontal operation revealed no pathologic changes in the region of the pituitary. The Wassermann test of fluid withdrawn from the lateral ventricle during operation was positive. All previous tests for syphilis had been negative.

A note from the husband, Nov. 1, 1920, stated: "Has been confined to her bed since (return from hospital); appetite exceptionally good and sleeps well but is gradually wasting away." 
Postoperative Notes.-The defect remained closed. The patient was discharged Nov. 1, 1919, with the neurologic condition unchanged.

Discharge Diagnosis.-Brain tumor was suspected; there was internal hydrocephalus of unknown etiology.

Comment.-The surgeon first became suspicious of tumor when the wound would not close without development of pressure symptoms. There was evidence to support such a suspicion. In the first place, no abscess was found, and the subsequent course of the disease argued against the presence of abscess. Furthermore it was early for the development of abscess. Also the surgical damage, bad as it was, could hardly have involved any portion but the temporal lobe, while progressive paralysis of the arm and leg developed.

It is stated that at the time of the first operation a cyst was opened and clear fluid escaped. It seems most probable that the surgeon made an opening into the lateral ventricle and continued to keep it open by packing until the foramen of Monro became occluded. When an attempt was made to close the exterior opening, a unilateral hydrocephalus developed, giving rise to headache, which was relieved by establishing a permanent sinus. After the sinus was finally closed here, considerable pressure developed for a day or two and disappeared, which we may perhaps explain by supposing that the foramen was again forced open, or even that an opening was forced through the septum pellucidum, as often happens in internal hydrocephalus.

Why the abscess was searched for in the temporal lobe is not certain. The staggering gait would indicate the cerebellum as the seat of trouble. If an abscess were present in the cerebellum, draining the lateral ventricle would relieve the pressure symptoms, but after such a long interval, closure of the drainage sinus would surely have led immediately to a recurrence of the symptoms, for although a brain abscess may heal spontaneously, it rerely does so.

There is even some question as to the condition of the eyegrounds prior to the first operation. The information at hand states that there was present bilateral choked disk with destruction of more than half of each retina. It seems most likely that the patient had an acute labyrinthitis, and that all his later troubles were due to operative trauma. The paralysis was probably caused by disturbance of circulation in the area of the middle cerebral artery when the hernia sloughed. ${ }^{7}$

7. Note from physician, Oct. 14, 1920, states: "Since his return from the hospital he has had several attacks of distention of the cyst which required drainage. He is now able to walk with a cane and move his left arm slightly. His eyesight is not improved in the least. . . His general health is good." 
CASE 6 (P.B.B.H. Surg. No. 10355). - Chronic circumscribed arachnoiditis with cerebellar tumor syndrome. Exploration. Death.

April 24, 1919, Joseph E., aged 33, a cigarmaker, referred from the outpatient department, was admitted with complaint of occipital headache and staggering gait.

Chronology of Symptoms.-March, 1912, the patient developed attacks of severe headache, usually suboccipital. The attacks increased in severity and were always accompanied by vomiting and dizziness. Meanwhile diplopia developed, and his eyesight began to fail. August, 1912, a right subtemporal decompression was made at the Massachusetts General Hospital which disclosed a tense brain but no other lesion. Following the operation there was rapid improvement. Headaches, vomiting, diplopia and dizziness ceased. August, 1915, the patient noticed an increasing clumsiness of the right hand so that he was obliged to discontinue work. August, 1918, attacks returned of severe suboccipital headache accompanied by stiffness of the neck and great unsteadiness of the gait. The attacks were increasing in frequency and severity.

Positive Findings.- These were: marked bilateral suboccipital tenderness and stiffness of the neck; staggering gait with greater tendency to fall to the right; diminution of muscle tone and power on right side, with incoordination, ataxia and adiadokokinesis; rotatory nystagmus downward and to the left on looking upward; secondary optic atrophy; cranial defect under right temporal muscle, not tense nor bulging; and an astereognosis of the right hand with some lowering of two-point discrimination. In short, there were definite signs of cerebellar involvement, but at the same time an unmistakable sign of involvement of the left parietal region of the cerebrum.

Clinical Diagnosis.-The case was diagnosed as a possible double meningeal endothelioma.

Operation.-The usual bilateral exposure was made May 14, 1919. The arachnoid was thickened and adherent to the dura, and in it were huge cystic spaces. The cerebellum was much deformed. The left hemisphere seemed about onehalf its normal size, and the right was almost totally destroyed, only the great fiber bundles remaining. On attempting to puncture the left ventricle much fluid was secured immediately under the dura so that there was undoubtedly here also an arachnoid cyst.

Postoperative Notes.-The patient recovered consciousness completely and the condition seemed satisfactory except for profuse sweating and hyperthermia until he died suddenly of respiratory failure thirty-six hours after the operation. Necropsy examination was refused.

Discharge Diagnosis.--Brain tumor was suspected; chronic circumscribed arachnoiditis.

Comment.-The presence of tumor was doubtful, without assuming the remote possibility of a double lesion. Of course, supratentorial tumors may give rise to slight cerebellar symptoms, but in this case both the cerebellar symptoms and the astereognosis were pronounced. Fearing a bad cerebellar seizure might prove fatal, an exploratory operation was considered justified.

CASE 7 (P.B.B.H. Surg. No. 10331).-Hysteria with cerebellar tumor syndrome. Exploration. Negative findings. Recovery. 
April 20, 1919, Charlotte R. K., aged 33, a school teacher, recommended by Dr. Joseph Stanton of Boston, Mass., was admitted to the hospital with complaint of headache, vomiting, dizziness, double vision and attacks of unconsciousness.

Chronology of Symptoms.-At 4 years of age the patient had had an otitis media following scarlet fever. In 1913, she had a ventral suspension of the uterus performed. In 1915, some friends persuaded her to have her ear operated on although, except for a slight discharge, it caused her no trouble. In July, 1915 , a radical mastoid operation was performed on her left ear. There was some delay in healing requiring skin graft, but final healing occurred in December, 1915. January, 1916, she suffered from nausea, double vision and severe dizziness. The symptoms subsided in ten days, but slight dizziness continued until summer. October, 1916, she had a similar attack accompanied by unconsciousness for three days at the onset. There was residual slight dizziness. January, 1918, she had a third attack accompanied by unconsciousness. Operation was performed through the external acoustic meatus. March, 1919, she had a fourth attack accompanied by unconsciousness. The old mastoid wound opened. Since that time she had remained in bed, never free from dizziness, nausea and double vision. She had had two other attacks of unconsciousness, one late in March and another just previous to admission.

Positive Findings.-These were: slight tortuosity of the veins of the retinae with obscuration of the nasal margins of the disks; paresis of the left facial nerve, apparently peripheral in type; Weber's test lateralized to the left ear; Rinne's test negative and auditory acuity much diminished in same; muscle tone markedly diminished on left side; Romberg sign positive; gait reeling with tendency to go to the left; slight incoordination of the left upper and lower extremities.

April 23, 1919, the patient was found in a strange semisomnolent state, with deep, rapid respirations, 24 per minute with expiratory grunt. She opened her eyes but did not respond to questions. The accessory respiratory muscles were called into play. The pupils were widely dilated. The veins of the fundi were dilated and tortuous, with edema of the nasal margins of the optic disks. There was no stiffness of the neck and no suboccipital tenderness. The rectal temperature was $99.2 \mathrm{~F}$. The leukocyte count was 16,400 .

Clinical Diagnosis.-This was possibly a case of extracerebellar tumor; there was probably a chronic arachnoid cyst of the left cerebellopontile angle. Consultation with Dr. Eugene Crockett, who concurred in this opinion.

Operation.-May 3, 1919, the usual suboccipital exposure was made. Although exploration of the left recess was carried down to the temporal bone and the seventh and eighth nerves were seen, no abnormality was disclosed.

Postoperative Notes.-The patient was extremely unruly during convalescence, screaming and crying almost constantly at first. She had one of her semisomnolent attacks, but was found at the same time to have secreted candy in her room, of which she consumed quantities. Suspicion growing that her troubles were mainly functional, she was given a vigorous lecture and became much more tractable. She was discharged June 7, 1919, with practically the same symptoms as on admission.

Discharge Diagnosis.-Brain tumor was suspected; hysteria.

Comment.-It was considered most probable that there was a circumscribed arachnoiditis in the angle. Acoustic tumor was possible since such cases often give a history of chronic otitis media. At least 
one good result came of the operation. She was cured of having operations.

Some time after operation a friend came to visit the patient. For apparently no reason the patient called me aside and told me not to talk to the woman for she was a great liar. Of course the friend was interviewed as soon as possible. She stated that she and the patient had lived alone for some years, and although she did not consider the patient insane, she thought the patient was never normal. Many times she tied the patient in bed at night to keep her from walking away. Attacks of semiconsciousness and speechlessness had been present several years previous to the first mastoid operation. The friend could always tell when an attack was coming on by the listless way the patient sat around. The relatives denied all knowledge of such occurrences. ${ }^{8}$

C. Clinically, Tumor.-In a single instance the diagnosis was not doubted, clinically, but no evidence of tumor was disclosed although the region was fully exposed. It seems equally certain now that no tumor was present, but necropsy examination is necessary for verification. The case follows:

CASE 8 (P.B.B.H. Surg. No. 10727).-Dyspituitrism zeith diabetes insipidus. Operation. Negative findings.

June 27, 1919, David S., aged 141/2, a schoolboy, recommended by Dr. Jacob Rosenbloom of Pittsburgh, was admitted to the hospital with complaint of poor vision and excessive thirst.

Chronology of Symptoms.-For the last ten or eleven years the patient had suffered from excessive thirst and polyuria. Sight had been failing for two years.

Positive Findings.-The findings were: bilateral primary optic atrophy; visual acuity about $10 / 50$ in each eye with a very small area of vision in the lower part of each field. The clinoid processes were greatly thickened There were slight skeletal undergrowth and feminine distribution of hair, but the genitalia were well developed and the voice was quite masculine. Libido was undeveloped; basal metabolism, -16 ; average water intake per diem, 8,500 c.c.; daily urine output about the same. The body temperature was very variable, 95 to $99 \mathrm{~F}$.

Clinical Diagnosis.-A diagnosis of supracellar cyst was made.

Operation.--July 14, 1919, the usual transfrontal procedure was carried out with no difficulty. The frontal lobe was easily elevated, and a good view was had of the chiasm. No evidence of any tumor was disclosed.

Postoperative Notes.-The condition remained unchanged until he was discharged July 31, 1919.

Discharge Diagnosis.-Brain tumor was suspected; diabetes insipidus. ${ }^{\circ}$

8. Note from the patient Oct. 24, 1920, states: "Dear Sir: In reply to your request of October 4, will say. . . that $I$ am able to work and as far as your records are concerned-condition is O.K."

9. A note from patient's sister, Oct. 8, 1920, stated: "We can notice no material improvement in his condition. His health is about the same, that is, it is very good in comparison to the condition of his eyes. He still maintains an enormous consumption of water . . . ." 
Comment.-In a very similar case, except for the diabetes, a cholesteatoma of the third ventricle was found. ${ }^{10}$

D. Verified Nontumors.-In 1904, Nonne ${ }^{11}$ described a series of cases which he tried to combine into a clinical entity characterized by more or less slow development of the picture of brain tumor. If death occurred, neither macroscopically nor microscopically was any adequate lesion discovered. To such a clinical picture, Nonne applied the term "pseudotumor cerebri."

Many similar cases have subsequently been reported, but always, when properly examined, definite histopathologic changes have been found and these of the most varied description. As has been pointed out elsewhere, ${ }^{3}$ the use of the term "pseudotumor" to refer to them is unfortunate. Malaria and miliary tuberculosis may simulate typhoid fever but to designate such instances as "pseudotyphoid" would only cause confusion. It is certain from a careful examination of lesions simulating tumor of the brain that no such clinical nor pathologic entity exists as Nonne tried to establish. Furthermore, tumor of the cerebellum is simulated at least as often as tumor of the cerebrum.

It has been decided in this clinic to discard the term "pseudotumor cerebri" although it is occasionally written in parenthesis after one of the brain tumor suspects to indicate that it might be such a condition as Nonne had in mind.

The rules for recognizing pseudotumors laid down by Nonne, ${ }^{12}$ in his last monograph on the subject, are copied from Higier as follows:

1. Evident infection, severe anemia, and physical and psychic trauma must be absent.

2. The onset must not be acute.

3. Signs of essential hydrocephalus must be absent (head deformity, etc.).

4. If recovery occurs, it must be gradual.

5. If death occurs, no pathologic changes must be found after thorough microscopic study.

There may have been cases at the time of Nonne's first publication (1904) in which no pathologic changes could be demonstrated, because the methods used were imperfect. Certainly every case examined by modern histopathologic methods, especially those for bringing out changes in the glia, has shown definite lesions.

10. Bailey, P.: Cruveilhier's “Tumeurs Perlèes," Surg. Gynec. \& Obstet. 31:390, 1920.

11. Nonne: Ueber Fälle vom Symptomencomplex von Tumor cerebri mit Ausgang in Heilung, Deutsche Zeitschr. f. Nervenheilk., 27:169, 1904.

12. Nonne: Der Pseudotumor cerebri, Neue deutsch. Chir. 10:107, 1914. (Die allgemeine Chirurgie der Gehirnkrankheiten, Part 2.) 
In the present series were two patients who had typical history and findings of localizable tumor. Concerning one, Lizabel McN., Surg. No. 11187, recorded in detail elsewhere, ${ }^{3}$ there will be no question. There was present a complete picture of tumor of the left cerebellar hemisphere. Histopathologic examination of the brain proved it to be a meningoencephalitis.

The history of the other case will be given and the propriety of its inclusion in this group discussed later.

CASE 9 (P.B.B.H. Surg. No. 10912).-Solitary tubercle of left cerebellar hemisphere. Removed at operation. Tuberculous meningitis. Death.

July 30, 1919, Stewart D., aged 27, a business man, was admitted to the hospital, recommended by Dr. Hoover of Cleveland, Ohio. He complained of headaches, vomiting and unsteady gait. The left testis and epididymis were removed in 1916 for tuberculosis.

Chronology of Symptoms.-For six months he has suffered with stiffness of the neck, for four months with dizziness and vomiting on arising; for three months with suboccipital pain, and for two weeks with a tendency to deviate to the right in walking and with unsteadiness of the right hand.

Positive Findings.-There were present: bilateral choked disk of I D.; marked nystagmus on looking to right and left and a positive Romberg sign. The gait was staggering. Slight ataxia was found in both hands, more noticeable in the left. There were also slight left facial weakness, suboccipital tenderness on both sides; the head was held tilted to right. Bradycardia was found.

Operation.-Aug. 1, 1919, under procain anesthesia a large solitary tubercle of left cerebellar hemisphere adherent to the dura was disclosed. It was removed intact by careful dissection with ample margin of brain tissue.

Postoperative Notes.-On August 17, the temperature was normal and the patient felt perfectly well. On August 23, there was afternoon temperature of $100 \mathrm{~F}$., and some stiffness and soreness of neck. On September 11, the temperature was falling; on Sept. 14, the patient became irrational.

Second Operation.-A parasagittal incision was made, September 16, into the old operative defect in bone on left side revealing a tuberculous meningitis. On September 19, the temperature was normal, the patient being irrational and incontinent. On September 22, the temperature was $97 \mathrm{~F}$. The patient died September 24 with temperature $105.4 \mathrm{~F}$.

Necropsy.-This was performed September 25, and revealed tuberculous meningitis, a small tuberculous cavity in apex of right lung and tuberculosis of prostate.

Discharge Diagnosis.-The diagnosis was tuberculosis of the prostate and right lung, tuberculoma of left cerebellar hemisphere, postoperative tuberculous meningitis.

Comment.-The possibility of tubercle was not overlooked here, although physical and roentgen-ray examinations of the chest were entirely negative. At any rate, surgical relief was indicated, for whether tubercle or tumor it was evidently interfering seriously with cerebrospinal fluid drainage.

There is some question as to whether tuberculoma and gumma should be included under the brain tumors. There is no doubt that 
both may give rise to typical tumor manifestations and even demand surgical removal. On the other hand, neither tubercle nor gumma is a neoplasm, but rather an infectious granuloma and the indications for surgical therapy are far from clear in many cases.

Although a solitary tubercle may be successfully removed, there is no way of knowing that others do not exist in the vicinity. If the surgeon cuts into one of these, infection of the meninges is almost certain. Even in the most favorable cases, such as the one just reported in which necropsy proved that only a single large tubercle was present, the result is very often utterly discouraging. Gummas may be much more safely removed, but it is rarely necessary. Certain old, hard, fibrous lesions may necessitate surgical removal, but most of them may be successfully combated by medical means.

These are border line conditions, and it is very difficult at times to know just where to draw the line. Multiple small tubercles may be present. Also, the astonishing thickening of the basilar meninges encountered at times in syphilitic basilar meningitis may simulate very closely suprasellar tumor. In order to emphasize the problems connected with these lesions, there is a tendency in this clinic to group the infectious granulomas with the tumor suspects.

\section{UNVERIFIED BRAIN TUMORS: TWENTY-FOUR CASES, '20.34 \\ PER CENT.}

The unverified brain tumors fall definitely into three groups. The meaning of the term "verification" will be explained under Group III.

A. Unoperated.-Of the thirteen unoperated cases, five operations were postponed merely for the convenience of the patient; four cases were thought to be pontine gliomas for which no operative procedure is of any avail; two were metastatic carcinomas; one patient was an acromegalic whose symptoms had been quiescent for twenty years; and in one case, probably a frontal glioma, the patient refused operation. In every case both pressure and localizing symptoms were present (except the pituitary cases in which pressure symptoms were absent).

$B$. Unlocalized.-Five patients had definite pressure syndromes but insufficient localizing symptoms. In such cases, a right subtemporal decompression was usually performed to relieve pressure and particularly to save vision menaced by choked disk, a procedure now well established in cranial surgery. In two of these cases, a large bone flap was turned down and converted into a decompression when no lesion was disclosed. At any rate, a definite attempt to reach a tumor was not made. 
C. Undisclosed.-Six times a definite attempt was made to remove a tumor, three times by a suboccipital approach, twice by a boneflap and once by a transsphenoidal approach. ${ }^{13}$ The lesions were not disclosed, and although in two cases in which a boneflap was turned down a cerebral glioma was certainly present, since a fragment was not removed for histologic study, these cases could not be listed as verified. Also by a suboccipital approach, it was impossible to verify a deep lying cerebellar glioma which had not broken down and become cystic. That the difference between verificaticn and nonverification may depend on a very small thing is shown in the case of P. P. (Surg. No. 10883) in which a fortunate puncture deep into the cerebellum struck a small gliomatous cyst from which a few drops of characteristic yellow fluid were sectred. He would otherwise have been included in this group. On the other hand there has been already noted under Group I, $D$ the case of L. McN. (Surg. No. 11187) originally placed in this group, who came to necropsy after this article was begun.

The cases in Group II are not so interesting as those in Group I. The presence of tumor was not doubted from clinical examinations, and during the operation nothing occurred to cast suspicion on the diagnosis.

III. VERIFIED BRAIN TUMORS: SIXTY-THREE CASES, 53.39 PER CENT.

This group will be dismissed with a few remarks. A number of cases have been already noted. They present few difficulties in classification except for the pathologist, and with the difficulties of pathologic diagnosis we are not here concerned. It will be noted that although the tumors verified include only 53.39 per cent. of all the cases quoted in this series, if we include only Groups II and III, they constitute 72.4 per cent. of the actual tumor cases (so far as it is possible to estimate the exact number at the present time). If we again exclude the unoperated cases in Group II, $A, 85.13$ per cent. of the operated tumor cases were verified. The members of this yroup were distributed pathologically as in the accompanying tabulation.

It is, of course, apparent that, in nearly two thirds of the cases, symptoms referable to the brain arose solely from the fact that the structures from which the tumors originated were enclosed in the cranium along with the brain. It will be observed that in this series the gliomas alone arose from the brain tissue. As has been often

13. This patient suddenly became unconscious, Sept. 15, 1920, while at work. He was taken to the Boston City Hospital where he died in a few hours. At necropsy there was found a tumor of the pituitary gland which had dissected its way extensively beneath the dura into the temporal fossae. 
stated before it would be well to abandon the term "brain tumor" for the more accurate and suggestive term "intracranial tumor."

A. Verified at Operation.-Tumors were never classified as verified at operation without removal of a fragment for histologic examination, with one exception-the straw-colored fluid which coagulates on standing, contained in a gliomatous cyst, can scarcely be mistaken for anything else.

Pathologic Distribution of Cases of Verified Brain Tumor

\begin{tabular}{|c|c|c|c|c|c|c|c|c|c|c|c|c|c|}
\hline & \multicolumn{6}{|c|}{ Cerebral } & \multicolumn{2}{|c|}{ Pituitary } & \multicolumn{2}{|c|}{ Cerebellar } & \multicolumn{2}{|c|}{ Brain Stem } & \multirow[b]{2}{*}{ 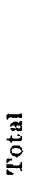 } \\
\hline & $\begin{array}{l}\text { 吾 } \\
\text { 营 } \\
\text { 点 }\end{array}$ & 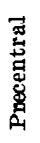 & 苞 & 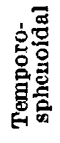 & 总 & 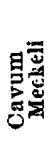 & 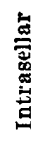 & 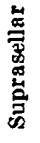 & 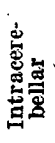 & 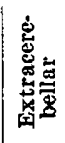 & $\begin{array}{l}\text { 莒 } \\
\text { ه }\end{array}$ & 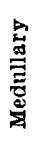 & \\
\hline Gliomas......... & 1 & 3 & 1 & $\mathbf{5}$ & 1 & & .. & $\because$ & 12 & $\cdots$ & .. & 1 & 24 \\
\hline Endotheliomas.. & 2 & $\mathbf{3}$ & 2 & 2 & .. & 1 & .. & 2 & .. & $\ddot{\theta}$ & .. & . & 12 \\
\hline$\underset{\text { (acoustic) }}{\text { Neuromas... }} \cdot \cdot$ & • & . & . & . & .. & *. & *. & . & $\cdots$ & 6 & . & . & 6 \\
\hline Adamantinoma. & .. & .. & .. & .. & $\cdots$ & 1 & .. & .. & .. & .. & .. & . & 1 \\
\hline Carcinoma....... & .. & . & .. & .. & .. & 1 & .. & $\because$ & .. & $\because$ & .. & .. & 1 \\
\hline Tumeurs perlées & .. & .. & . & $\because$ & . & . & ii & 1 & . & 1 & . & .. & 2 \\
\hline Adenomas............ & ". & - & $\cdots$ & *. & $\cdots$ & .. & 11 & $\cdots$ & .. & $\cdot \cdot$ & $\cdots$ & .. & 11 \\
\hline Congenital eysts & .. & .. & .. & .. & .. & .. & 2 & 2 & .. & .. & .. & .. & 4 \\
\hline $\begin{array}{l}\text { linithelioma...... } \\
\text { (Rathke's } \\
\text { fouch) }\end{array}$ & *. & . & $*$ & .. & $\cdots$ & .. & .. & 1 & .. & .. & .. & .. & 1 \\
\hline $\begin{array}{c}\text { Fapilloma } \\
\text { (choroid } \\
\text { pitxus) }\end{array}$ & .. & .. & $\cdot \cdot$ & .. & 1 & .. & *. & . & .. & . & * & $\cdot \cdot$ & 1 \\
\hline Total......... & 3 & 6 & 3 & 7 & 2 & 3 & 13 & 6 & 12 & 7 & 0 & $\mathbf{1}$ & 63 \\
\hline
\end{tabular}

Many of the cases, except for accident, would of necessity have been classified as unverified. One case in point is E. T. (Surg. No. 10572). A glioma of the medulla oblongata was exposed at operation. It was evidently impossible to remove a piece of tumor for histologic examination although the nature of the condition was unquestionable. The patient subsequently died of respiratory paralysis and the history came up for discussion before the pathologist's report was received. I proposed that the case be put in Group III $A$ as a tumor verified at operation, but Dr. Cushing protested. When the diagnosis of glioma was established by histologic examination of the necropsy specimen, and then only, was the case classified in Group III $D$.

$B$. Verified at Necropsy.-The single unoperated case is noteworthy for the reason that had necropsy been refused it would have been relegated to the group of suspects .

CASE 10 (P.B.B.H. Med. No. 11985).-Abscess of the frontal lobe, with concurrent endothelioma. Death. Necropsy.

Oct. 8, 1919, Frederick S., aged 50, an optician, recommended by Dr. Belle, of Waltham, Mass., was admitted complaining of "brain tumor." 
Chronology of Symptoms.-For one year, occasional trancelike states had occurred at night. The patient would wake up and feel he could not move. For thirteen weeks there had been pain in the upper teeth on the left side spreading along to the eye and then to the head, lately it had been very severe in the left temporal region and constant, keeping him awake at night. Four weeks previously the left upper molar tooth had been removed for abscess at the root. For one week there had been occasional vomiting with slight nausea, photophobia, flashes before the eyes and failing vision. For five days he had suffered difficulty in swallowing and speaking and disturbance of the sense of smell and taste. For four days there had been rigidity of the neck and for two days he had been totally blind.

Positive Findings.--The rectal temperature was $99.8 \mathrm{~F}$. There was rigidity of the neck. The reflexes were hyperactive. The pupils dilated without reaction to light. There were right external rectus paresis; complete left opthalmoplegia and profound stupor. The right optic disk was edematous, hyperemic and elevated $1 / 2 \mathrm{D}$, the left was elevated $1 \mathrm{D}$. The leukocyte count was 18,000 .

Course.-October 9, poorly sustained ankle clonus was observed on the right side and positive Kernig sign on the left. October 12, transillumination of the sinuses was negative. October 16, the findings were ptosis of the left eyelid, ankle clonus on both sides and normal temperature. October 18, lumbar puncture revealed straw-colored fluid with 465 polymorphonuclear leukocytes per cubic mm. October 19, the patient died.

Necropsy.-This revealed dural endothelioma in the region of the sphenoidal wing in the left middle fossa; abscess of the left frontal lobe; purulent meningitis and suppuration of the left maxillary and sphenoidal sinuses.

Comment.-The whole course of this case distracted one's attention from the possibility of tumor. The only clue we get in the history is furnished by the story of peculiar trancelike states for a year previous to admission. Such states accompanied by a sense of unreality are well known in temporal lobe tumors and in this case were doubtless due to the tumor.

C. Verified at Operation and Necropsy.-The single case verified at operation, which subsequently came to necropsy (C. M., Surg. No. 11078), was an extensive glioma of the left cerebral hemisphere. This patient had been previously operated on by Sir Victor Horsley, presumably for jacksonian epilepsy.

D. Verified at Necropsy, Unverified at Operation.-Of the four cases unverified at operation and verified later at necropsy, one (M. C., Surg. No. 10252) was an extensive glioma of the thalamus with an advanced secondary hydrocephalus; another patient (T. H., Surg. No. 11462), had a bilateral papilloma of the lateral choroid plexuses; a third (E. T., Surg. No. 10572) an extensive glioma of the medulla oblongata; and the fourth (A. B., Surg. No. 10231) an extensive glioma of the right frontal lobe whose only symptoms were those of a suprasellar tumor. A transfrontal procedure was adopted with the last patient. The findings were negative, and death occurred some weeks subsequently at her home, the brain being sent to us by her physician. 
Finally, it is important to call attention to the fact that in the last group of tumors, verified, the clinical picture was often no clearer than in the cases given under Group I, $B$ or Group II, $C$. The following is an unusually valuable case in point.

CAse 11 (P.B.B.H. Surg. No. 10681).-Endothelioma of left cerebral hemisphere with faccid paralysis of right arm. Extirpation. Recovery.

June 20, 1919, Dorothy R., aged 22, a student, was admitted complaining of paralysis of the right arm, weakness of the right leg and headache.

There had been panophthalmitis in the right eye, at 10 years of age, following an injury, accompanied by sympathetic inflammation of the other eye. Vision was much obscured in each eye.

Chronology of Symptoms.-In 1914, there were attacks of peculiar sensation, like an electric shock in the right hand. Later attacks involved the right arm and face. September, 1918, motor weakness began in the right arm. For one month, there was weakness of the right foot; for one month, headaches; for one week, vomiting following headaches. There was a vague history of rare attacks of twitching in the right arm elicited after much questioning.

Positive Findings.-No sign of sensory defect was detected except absence of abdominal reflexes on the right side. There was marked hypotonicity of the musculature of the entire right half of the body, most marked in the right arm, which showed total flaccid paralysis except for slight movement in the biceps and deltoid. Motor weakness, so marked in the arm, was slight in the leg and barely perceptible in the face. Tendon reflexes were exaggerated, on the right side, very slightly exaggerated in the arm, more so in the leg. There was a suggestive Babinski sign and a poorly sustained ankle clonus on the right. There was atrophy of the interossei muscles of the right hand. Accurate ophthalmoscopic and perimetric observations were impossible because of cloudiness of the media from old inflammation.

Clinical Diagnosis.-Endothelioma of the left precentral region was the diagnosis.

Operation.-Osteoplastic exposure of the left cerebral hemisphere was performed July 8, 1919. A $32 \mathrm{gm}$. nodular endothelioma was removed from the precentral area.

Discharge Diagnosis.-Brain tumor was verified: endothelioma.

Comment.-This patient had been treated by an excellent neurologist for a "neurosis" and by another for an "occupational neuritis." She was at that time studying with a famous pianist. The total absence of spasticity, the marked hypotonicity, the absence of sensory signs, the vagueness of the history of motor attacks elicited after questioning and possibly due to suggestion, the slight but unmistakable atrophy of the interossei of the right hand, the absence of subjective symptoms of headache and vomiting since admission, the difficulty of making proper opthalmoscopic examination, all these things made it very hard to come to a decision in this case. Furthermore, she was the only child of very evidently psychopathic parents. She was kept under observation for some time, and operation was finally decided on as a result 
of exacerbation of headaches and vomiting, coupled with the presence of a Babinski sign and ankle clonus in the right foot. Undoubtedly, if she had come to us a month earlier, before headache and vomiting had appeared and possibly before the development of motor signs in the right foot, no operation would have been undertaken.

\section{SUM M ARY}

There has been given an account of the method used to classify clinically patients having, or supposed to have, intracranial tumors, in the hope that it will be of value in interpreting statistics from this clinic and perhaps assist in unifying general usage in this regard.

My thanks are due to Dr. Harvey Cushing for permission to publish these cases as well as for valuable suggestions in the preparation of this article. 